\title{
Influence of Tool Surface on Tribological Conditions in Conventional and Dry Sheet Metal Forming
}

\author{
Marion Merklein', Kolja Andreas', and Jennifer Steiner, ${ }^{1, \#}$ \\ 1 Institute of Manufacturing Technology, Friedrich-Alexander-University Erlangen-Nuremberg, Egerlandstr. 13, 91058 Erlangen, Germany \\ \# Corresponding Author / E-mail: Jennifer.steiner@fau.de, TEL: +49-9131-85-27954, FAX: +49-9131-85-27141
}

KEYWORDS: Sheet metal forming, Tribology, Dry forming

\begin{abstract}
The realization of lubricant free forming processes is motivated by an increasing demand for resource efficiency and higher environmental standards. Further potentials are the reduction of production steps and time. The dry conditions lead to an intensive interaction between tool and workpiece. Increasing friction and wear are the consequences. One approach to face these challenges is the implementation of tailored tool surfaces. Within this study the behavior of different tool surfaces under dry and lubricated conditions is investigated. In this regards, a flat strip drawing test was conducted to determine the friction coefficients depending on the tool surface properties resulting from various machining processes. Furthermore, a surface characterization before and after the experiments was performed to gain knowledge about the wear mechanisms. The tests series with dry strips lead to a higher friction level. Furthermore, the results show that the friction can be reduced when the grinding marks are orientated transversal to the drawing direction. A further friction reduction is achieved when applying polished tools.
\end{abstract}

\section{NOMENCLATURE}
$\mathrm{m}=$ Amount of lubrication
$\mathrm{p}_{\mathrm{N}}=$ Normal pressure
$\mathrm{v}_{\text {rel }}=$ Relative velocity
$\mathrm{n}=$ Number of repetition
$\mathrm{F}_{\mathrm{F}}=$ Friction force
$\mathrm{F}_{\mathrm{N}}=$ Normal force
$\mathrm{F}_{\mathrm{FU}}=$ Upper friction force
$\mathrm{F}_{\mathrm{FL}}=$ Lower friction force
$\mu=$ Friction coefficient
$\mathrm{Rz}=$ Averaged roughness height
$\lambda_{\mathrm{c}}=$ Cut off length
$\lambda_{\mathrm{S}}=$ Short-wave profile filter
$1_{\mathrm{r}}=$ Sampling length
$\mathrm{l}_{\mathrm{n}}=$ Measuring length

\section{Introduction}

Sheet metal forming processes like deep drawing are widespread deployed in the automobile industry for manufacturing car body parts. ${ }^{1}$ Understanding the tribological conditions within the forming operations is mandatory to design high-quality parts and to reduce the risk of production failures. ${ }^{2}$ Conventionally, lubricants are applied on the sheet metal surface to guarantee favorable tribological conditions. Many lubricants are mineral oil based and thus environmental harmful. ${ }^{3}$ Current trends for green production technologies force the abandonment of lubrication. Besides environmental efforts, the demand for an efficient usage of resources motivates the realization of dry forming processes. Vollertsen et al. recently introduced a process chain based definition of dry forming processes. According to this definition dry forming processes are characterized by the fact that the workpiece leaves the forming tool without the necessity of cleaning or drying before further production steps are applied. ${ }^{4}$ Therefore, reduction of process steps and shorter production times may be the consequences of dry forming processes. However, designing of forming processes without lubrication faces several challenges. The direct contact between tool and workpiece leads to an intense interaction which results in increasing friction and wear. In the end, this will cause shorter 
tool life and decreasing quality of the formed part. To overcome these drawbacks tailored tool surfaces can help to improve the tribological conditions in dry forming processes. Therefore, gaining knowledge about the influences of varying tool surface properties on the tribology of dry systems is one key factor for successful implementation of lubricant free deep drawing processes. Former studies already showed that the surface properties of the forming tool have a significant influence on the friction and wear behavior under lubricated conditions. ${ }^{5}$ Within this study different finishing strategies were applied on the tool surface. Their tribological performance was investigated by strip drawing tests under dry conditions. Additional experiments were conducted with lubricated specimens as reference. The overall aim of this study is to analyze the correlation between tool surface properties and friction as well as wear development in conventional and dry sheet metal processes.

\section{Experiment}

\subsection{Experimental Design}

In order to investigate the influence of the tool surface properties on the tribological conditions strip drawing tests were performed. The experimental design is visualized in Table 1 Experimental design and test parameters. The cold working steel 1.2379 was selected as material for the friction jaws. Common tools for deep drawing processes are often machined by combined grinding and polishing processes. The grinding was performed with two different grinding wheels to analyze if smoother surfaces lead to decreasing friction. The rough surface quality was ground by a corundum wheel with a coarseness of 80 . For finishing the smoothly ground jaws a cubic crystalline boron nitride $(\mathrm{CBN})$ wheel with a coarseness of 126 was used. Ground surfaces have a predominant direction depending on the orientation to the grinding wheel. In order to analyze the influence of the preferential direction on the tribological conditions the friction jaws were machined in $0^{\circ}$ and $90^{\circ}$ to the drawing direction. Furthermore, polishing was taken into account for the machining of the friction jaws to investigate even smoother surfaces without a preferential direction. The rough ground tools were first lapped and then polished with an oil based diamond suspension with a grain size of $9 \mu \mathrm{m}$. Some of the polished tools were additionally stepwise polished by hand with abrasive paper up to a coarseness of 4000 and finished with a quartz based silver care paste. As specimen material the mild deep drawing steel DC04 with a sheet thickness of $1.0 \mathrm{~mm}$ was selected. A zinc coating is applied on both sides of the sheet to provide a corrosion protective layer. For the investigation of dry conditions the basic lubrication was removed by cleaning the strips with acetone. In order to compare the results with conventional drawing processes specimens of further test series were lubricated manually by a foam role after cleaning. For lubrication the deep drawing oil KTL N 16 with a viscosity of $160 \mathrm{~mm}^{2} / \mathrm{s}$ at $40^{\circ} \mathrm{C}$ was applied. The oil film thickness is defined to $m=2.0 \mathrm{~g} / \mathrm{m}^{2}$ which represents a common amount of lubrication in the production of car body parts. ${ }^{6}$ The tests were performed with a drawing velocity of $100 \mathrm{~mm} / \mathrm{s}$ and a contact pressure of $1.0 \mathrm{MPa}$. These parameters represent typical relative velocity and load conditions in the flange area of a drawing process. ${ }^{7}$ Surface characterization was done for the friction jaws and the sheet metal strips by optical and tactile stylus measuring systems. The topography was analyzed by confocal microscopy on a NanoFocus " $\mu$ Surf" microscope with $20 \times$ magnification. The characterization was performed for the initial state and the surface properties after the strip drawing tests.

In Fig. 1 the defined measuring areas are shown for the frictions jaws and the sheet metal strips. The friction jaws were measured at the contact area of the strip edge and the tool surface because this area is characterized by the occurrence of extensive wear. The measuring area for the strip is selected in the center of the contact area.

The surface characterization was used to find explanations for the effects and correlations analyzed in the strip drawing tests. Differences between the wear mechanisms under dry and lubricated conditions are discussed in this paper. Fig. 2 exemplarily shows topographies of the friction jaws before testing. The rough ground tool in Fig. 2(a) has a raw surface with high profile depths. When the CBN wheel is applied, a smoother surface can be achieved (Fig. 2(b)). Both surfaces reveal a preferential direction. In contrast, the polished friction jaws in Figs. 2(c) and 2(d) have an undirected topography. The smooth polished tool in Fig. 2(d) reveals a more even surface structure than the rough polished one in Fig. 2(c).

The roughness was measured by a "Mar Surf GD 120" referring to DIN 4768. On each friction jaw 5 profiles were evaluated in order to guarantee the statistical significance. shows the arithmetic mean roughness $R a$ and the averaged roughness height $R z$ for each configuration. The measurements were performed perpendicular to the grinding marks. The polished tools were orientated transversal to the drawing direction. The values of $R z$ are approximately ten times higher than the $R a$ values. The $R z$ for the rough ground tools vary from 2.3 to $3.7 \mu \mathrm{m}$ depending on the grinding direction. Smoother surfaces with $R z$

Table 1 Experimental design and test parameters

\begin{tabular}{cccc}
\hline \multicolumn{2}{c}{ Friction jaw machining } & \multicolumn{2}{c}{ Lubricational conditions } \\
\cline { 1 - 2 } Surface finishing & $\begin{array}{c}\text { Preferential } \\
\text { direction }\end{array}$ & $\begin{array}{c}\text { Lubricated } \\
2.0 \mathrm{~g} / \mathrm{m}^{2}\end{array}$ & $\begin{array}{c}\text { Dry } \\
0.0 \mathrm{~g} / \mathrm{m}^{2}\end{array}$ \\
\cline { 1 - 2 } Rough ground & $0^{\circ}$ & & \multirow{2}{*}{$\mathrm{p}_{\mathrm{N}}=1.0 \mathrm{MPa}$} \\
$\mathrm{V}_{\mathrm{rel}}=100 \mathrm{~mm} / \mathrm{s}$ \\
Rough ground & $90^{\circ}$ & & $\mathrm{n}=5$ \\
Smooth ground & $0^{\circ}$ & & \\
\hline Smooth ground & $90^{\circ}$ & & \\
\hline Rough polished & - & & \\
\hline Smooth polished & - & &
\end{tabular}

(a) Friction jaw

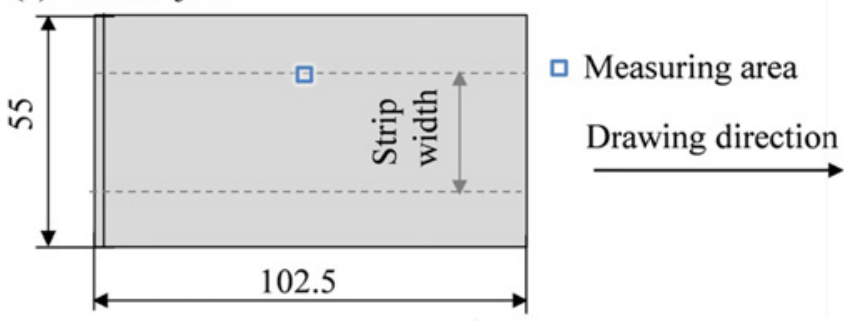

(b) Strip Contact area Clamping area

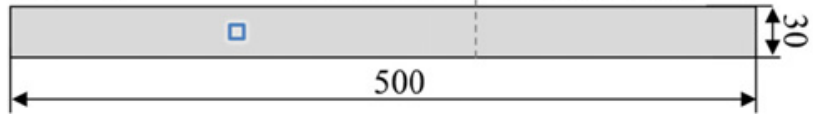

Fig. 1 Specimen geometry and location of measuring areas 
values of 0.6 to $0.7 \mu \mathrm{m}$ were achieved with the $\mathrm{CBN}$ wheel. The rough polished tools have approximately the same roughness like the smooth grounded but without preferential direction. With an averaged roughness height of $0.5 \mu \mathrm{m}$ the smooth polished friction jaws reveal the lowest $R z$ values.

The initial surface of the sheet metal strips are exemplarily measured for 10 strips. Fig. 3 shows a representative surface of a sheet metal strip. The investigated DC04 is structured with an electrical discharge texture (EDT) which typically reveals in a stochastic structure of valleys and peaks. The value of the averaged roughness height is in the range of 5.2 to $5.6 \mu \mathrm{m}$.

\subsection{Experimental Setup}

The influence of varying surface properties on the friction coefficient was investigated in the flat strip drawing test. The test setup shown in Fig. 4 is commonly used as a model experiment to analyze the friction in deep drawing

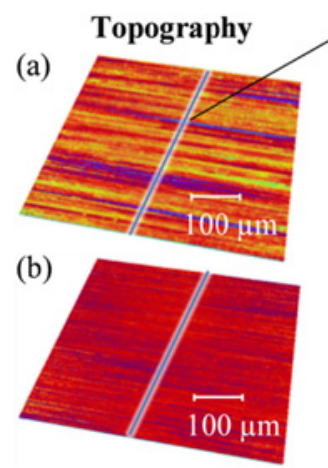

\section{Surface profile}
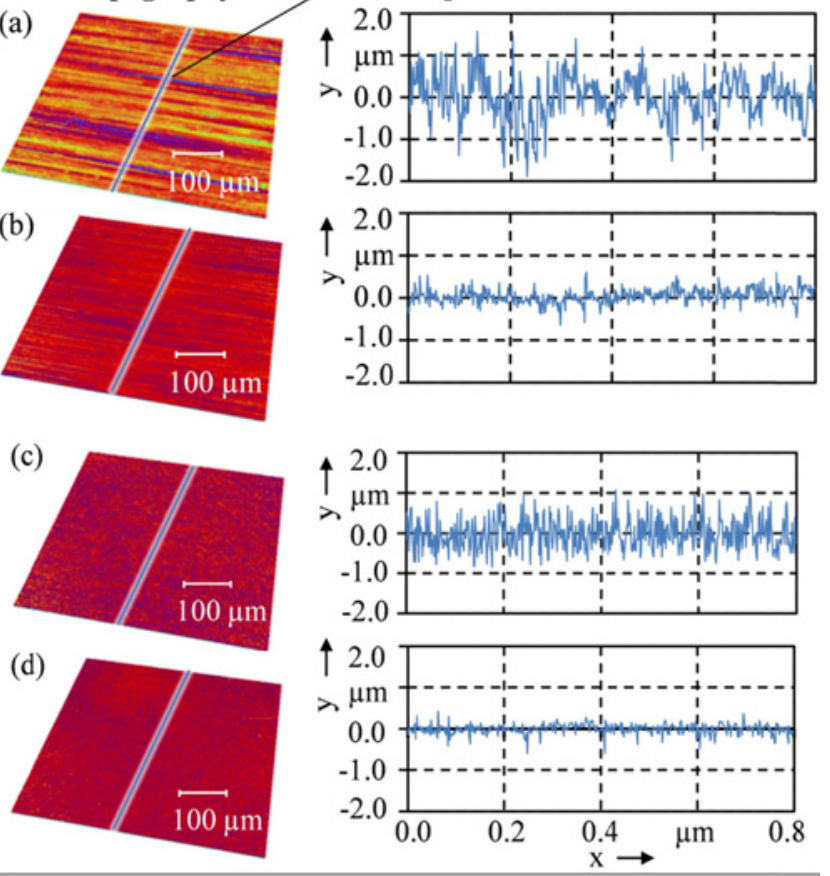

\begin{tabular}{|c|c|}
\hline $\begin{array}{l}\text { Initial tool surface } \\
\text { Lens } 20 \mathrm{x}\end{array}$ & 2nd degree polynomial \\
\hline Profile depth & $0.0 \quad 3.0 \mu \mathrm{m}$ \\
\hline
\end{tabular}

Fig. 2 Surface properties of initial tool topography

Table 2 Arithmetic mean roughness $R a$ and averaged roughness height $R z$ for investigated tool surfaces

\begin{tabular}{ccc}
\hline$R a[\mu \mathrm{m}]$ & $0^{\circ}$ & $90^{\circ}$ \\
\hline Rough ground & $0.23+/-0.03$ & $0.45+/-0.07$ \\
\hline Smooth ground & $0.06+/-0.01$ & $0.07+/-0.01$ \\
\hline Polished & Rough & Smooth \\
\hline & $0.10+/-0.01$ & $0.04+/-0.01$ \\
\hline$R z[\mu \mathrm{m}]$ & $0^{\circ}$ & $90^{\circ}$ \\
\hline Rough ground & $2.3+/-0.4$ & $3.7+/-0.8$ \\
\hline Smooth ground & $0.6+/-0.1$ & $0.7+/-0.1$ \\
\hline Polished & Rough & Smooth \\
\hline & $0.8+/-0.1$ & $0.5+/-0.1$
\end{tabular}

$\lambda_{\mathrm{c}}=0.8 \mathrm{~mm} ; \lambda_{\mathrm{s}}=2.5 \mu \mathrm{m} ; 1_{\mathrm{r}} / \mathrm{l}_{\mathrm{n}}=0.8 / 0.4 ; \mathrm{n}_{\text {profile }}=5$ processes. ${ }^{8}$ The sheet metal strip is positioned between the friction jaws. The lower friction jaw moves upwards and applies a defined normal force. When the strip is drawn through the friction jaws the drawing force is measured.

The drawing force represents the friction force $F_{F}$. The friction coefficient $\mu$ is computed according to the Coulomb friction law where $\mu$ is proportional to the normal force $F_{N}$ and the friction force $F_{F}$

$$
\mu=\left(F_{F} / 2\right) / F_{N}
$$

Shows the progression of the friction force against the drawing length $l$. First, the friction force increases due to static friction. After overcoming the static friction the force drops to the stable level of sliding friction. After $170 \mathrm{~mm}$ the slowing down of the drawing velocity leads to an increasing friction force. In order to analyze stable conditions the evaluation area for computing the friction coefficient is set between 100 and $170 \mathrm{~mm}$.

\section{Results}

\subsection{Friction Determination}

For each tool surface 5 strips were drawn under lubricated and dry conditions. New friction jaws were applied for each test configuration. Fig. 6 shows the results for the lubricated system. With an increasing tool surface quality the friction is decreasing. Thus, the rough ground

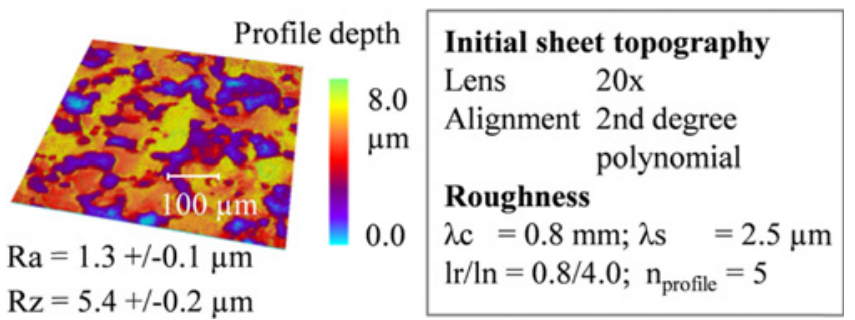

Fig. 3 Initial topography and roughness of the sheet metal surface

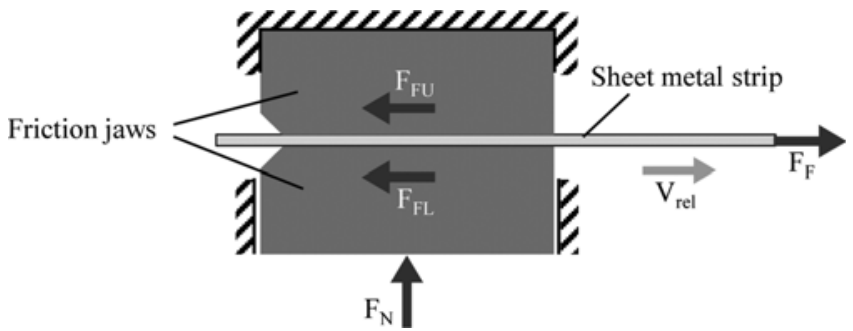

Fig. 4 Schematic test setup of strip drawing test

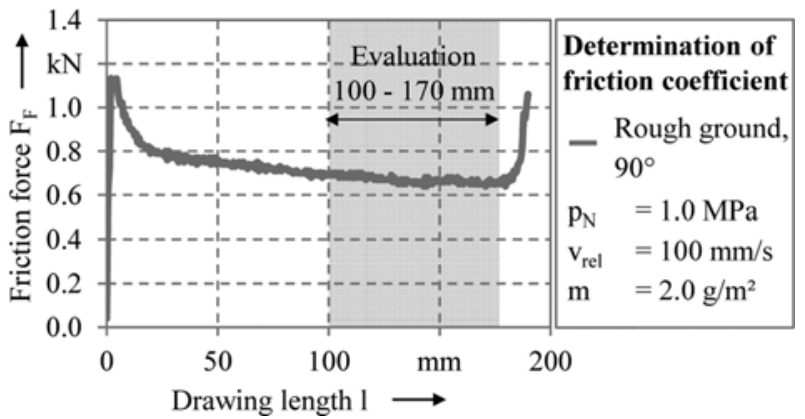

Fig. 5 Friction force - drawing length curve for friction determination 
friction jaws lead to the highest friction coefficients. The influence of the preferential direction of ground surfaces is not detectable. The friction coefficients for the rough ground tools vary between 0.08 for the ground marks in drawing direction and 0.11 for the transversal preferential direction. When smooth ground surfaces were applied the friction is reduced to a level of 0.05 . The lowest friction coefficient of 0.04 was achieved with the rough polished friction jaws. A slight increase of 0.01 is detected for the smooth polished tools.

Additionally, dry test series were performed. The resulting friction coefficients are presented in Fig. 7. As expected the resulting friction coefficients are higher compared to the lubricated tests. Furthermore, the correlations between tool surfaces and friction coefficients differ. The highest friction coefficient with an average value of 0.27 and a maximum of 0.29 occur when applying friction jaws with the smoother surface which are ground in drawing direction. In contrast, smooth polished tools show the lowest friction with a minimum value of 0.19. The friction jaws which are ground transversely to the drawing direction indicate lower friction coefficients between 0.22 for the rough and 0.23 for the smooth ground tools. The polished friction jaws result in a low friction level about 0.20 . There is just a minor difference of 0.01 in the friction coefficient between the two polishing qualities.

\subsection{Surface Characterization}

In order to confirm the qualitative correlations between friction coefficients and tool machining a surface characterization was performed. The measurement was conducted at the contact area of the strip edge and the friction jaw. To enable direct comparison between the lubricated and dry test series the same resolution was used in Figs. 8 and 9. Fig. 8 Tool topography after lubricated strip drawing test depicts the topography of the friction jaws after the lubricated strip drawing test.

Minor adhesion occurs on the rough ground tool surfaces. This

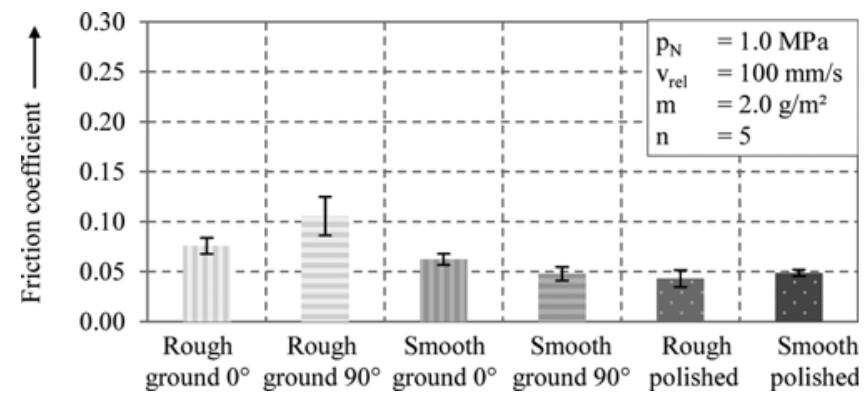

Fig. 6 Friction coefficients under lubricated conditions

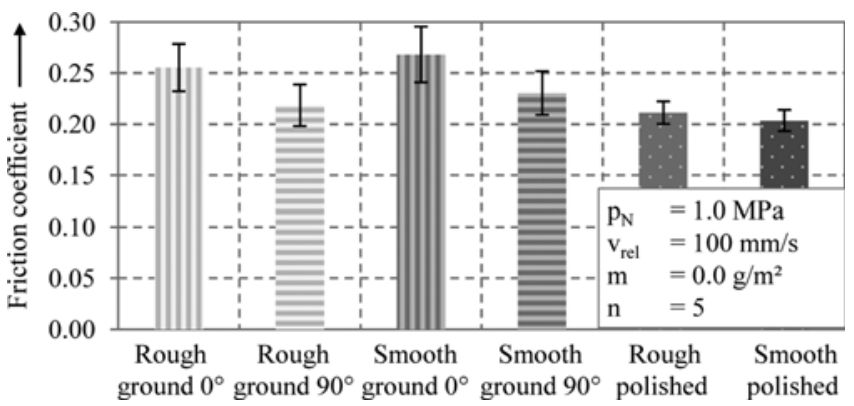

Fig. 7 Friction coefficients under dry conditions might be the reason why these test configurations lead to the highest friction coefficients. On the smooth ground and polished tool surfaces no sign of wear in terms of adhesion is detected. The tool topographies after performing dry experiments are presented in Fig. 9. The tribological systems with higher friction coefficients also show severe adhesive wear on the tool after drawing of 5 strips. A strong tendency

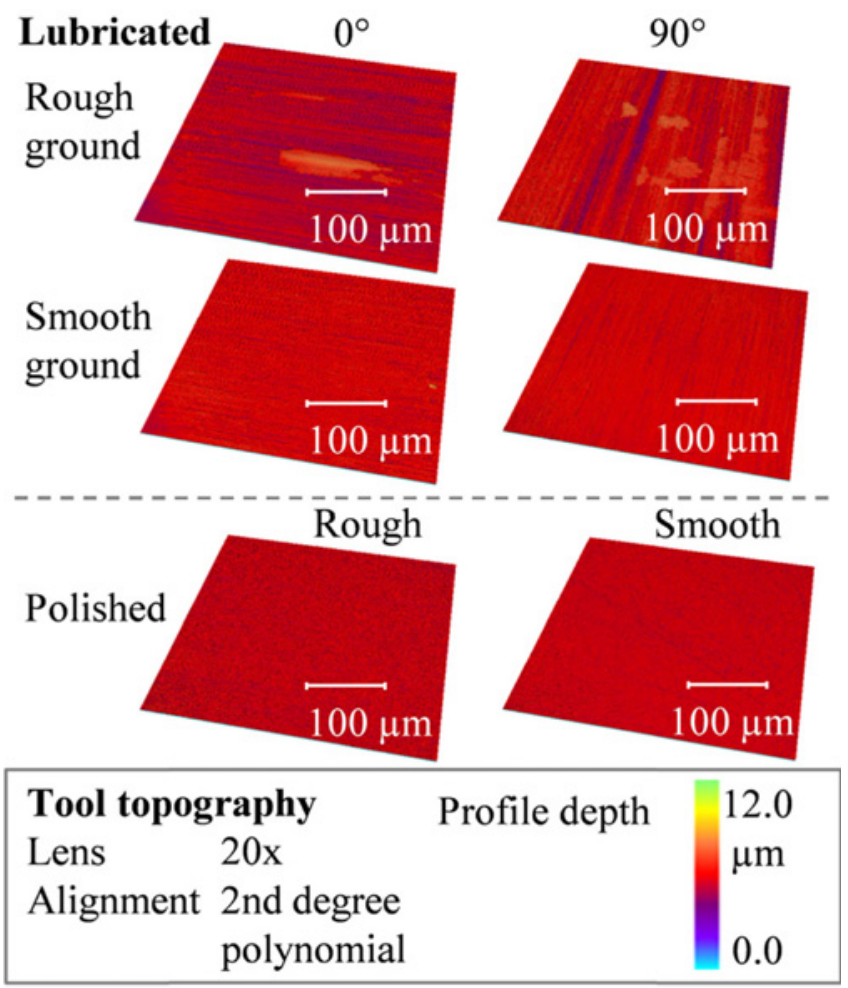

Fig. 8 Tool topography after lubricated strip drawing test
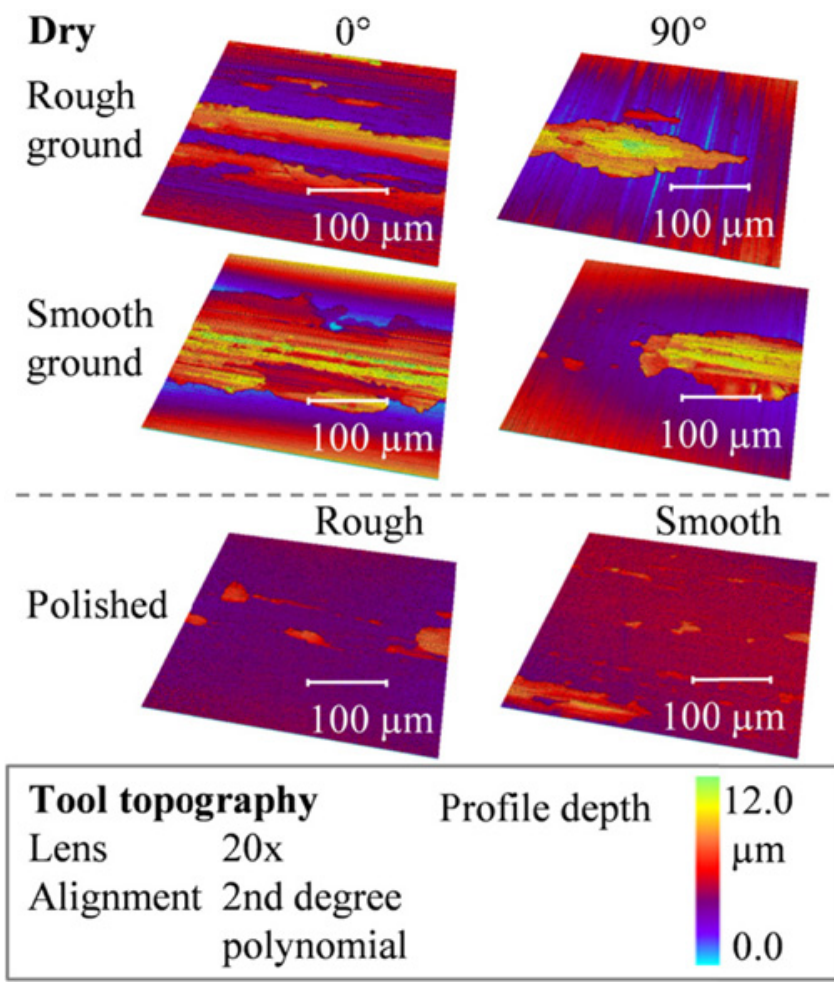

Fig. 9 Tool topography after dry strip drawing test 
for adhesion reveals for the tools which are ground in drawing direction. When grinding marks are orientated transversely the adhesion is reduced. As expected, the polished friction jaws show minor adhesion of the sheet material compared to the ground ones. Besides, the tool topography the surface of the sheet metal strips was characterized after the test. For each series the last drawn strip was measured. A position in the strip center is defined as the measuring area as shown in Fig. 1. Fig. 10 depicts the results of the optical measurement of the strips under lubricated conditions. A smoothening of the strip surface is detected for the experiments with the ground friction jaws. A comparison between the ground test series reveals that only transversally rough ground tool evokes an evident reduction of the roughness peaks of the workpiece. This leads to a flattening of the sheet topography. The plastic deformation on the sheet surface might be the reason why this test series reaches the maximum friction coefficient of 0.13 under lubricated conditions as shown in. The sheet metal surfaces which were in contact with the polished tools show only slight flattening. There are no signs of abrasion on the sheets when lubrication is applied.

The same measuring procedure was applied for the dry experiments. Exemplarily surfaces are given in Fig. 11. The interaction in the contact zone is determined by the lubricational conditions. Whereas the lubricated strips reveal only slight indications of flattening processes and abrasion, the surface properties of the dry strips show changes in the topography.

On the sheet surfaces no adhesion but abrasion phenomenon could be detected. The reason for this is that the tool hardness of $60 \mathrm{HRC}$ is much higher than the hardness of the zinc layer on the sheet metal strips. As expected from the resulting friction coefficients the strongest wear occurs when the friction jaws are ground in drawing direction.

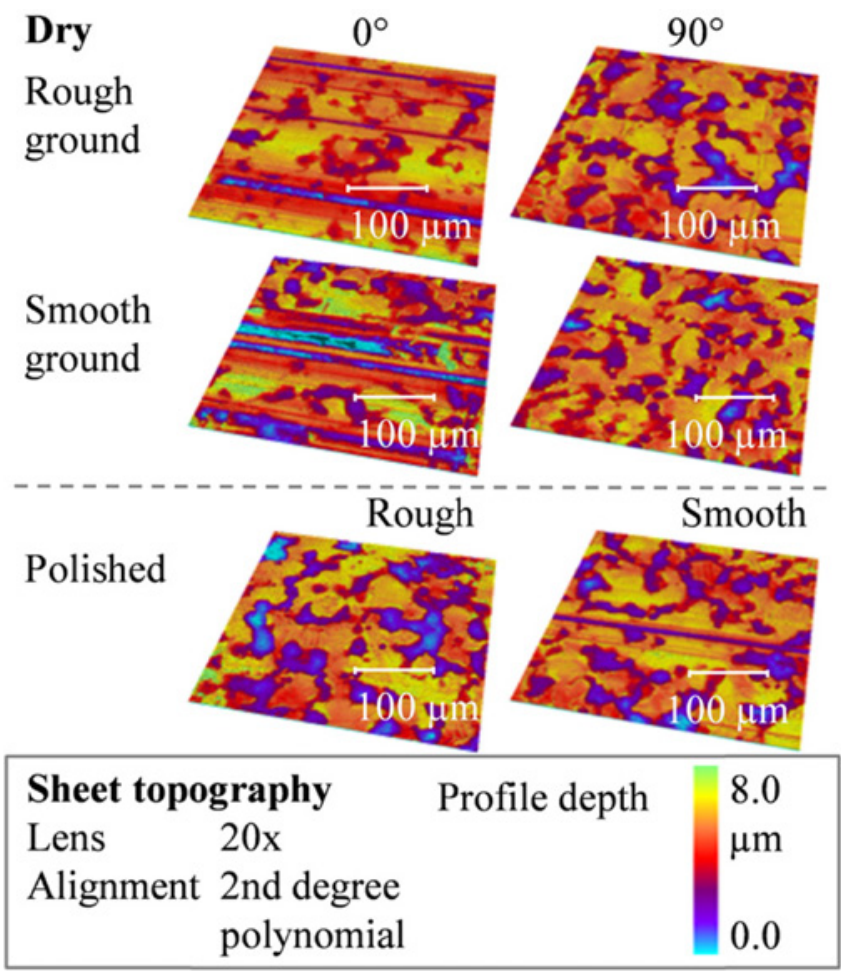

Fig. 10 Sheet topography for strip 5 after lubricated strip drawing test
Here some score marks in drawing direction groove the zinc layer. When comparing these results with the initial sheet surface in Fig. 3 smoothening of the topography is evident, this leads to a flattened surface with smaller roughness peaks.

\section{Discussion}

The general correlations between tool surfaces and friction are determined by the lubrication conditions. The influence of the preferential direction with lubricated strips is not as clear as for the dry conditions. The highest friction in the lubricated test series occur with transversally ground jaws. The lubricant certainly flows out at the edge of the tool. In contrast, when applying the tools ground in $0^{\circ}$ the outer grinding rims might cause a stopping of lubrication outflow. However, these effects are mainly observed at the tests series with the rough ground tools. Lowest friction levels are detected when the frictions jaws have an undirected polished surface. Under these conditions the oil film can disseminate homogenously between the tool and the specimen. The lubrication does not descend in the valleys of the grinding structure. Thus, with the same amount of lubrication the polished jaws tend to reduce the friction coefficients slightly. In the lubricated tests, the rough polished tools lead to the lowest friction coefficient although the smooth ground and smooth polished jaws have a smaller surface roughness. Therefore, the friction seems to have a minimum at a medium surface roughness. Beyond this roughness level further improvement of the surface quality will lead to increasing friction. The reason might be that the oil retaining capacity is decreasing on too smooth surfaces. That effect is already known for the sheet surfaces and is the reason why a texture is applied on the sheets

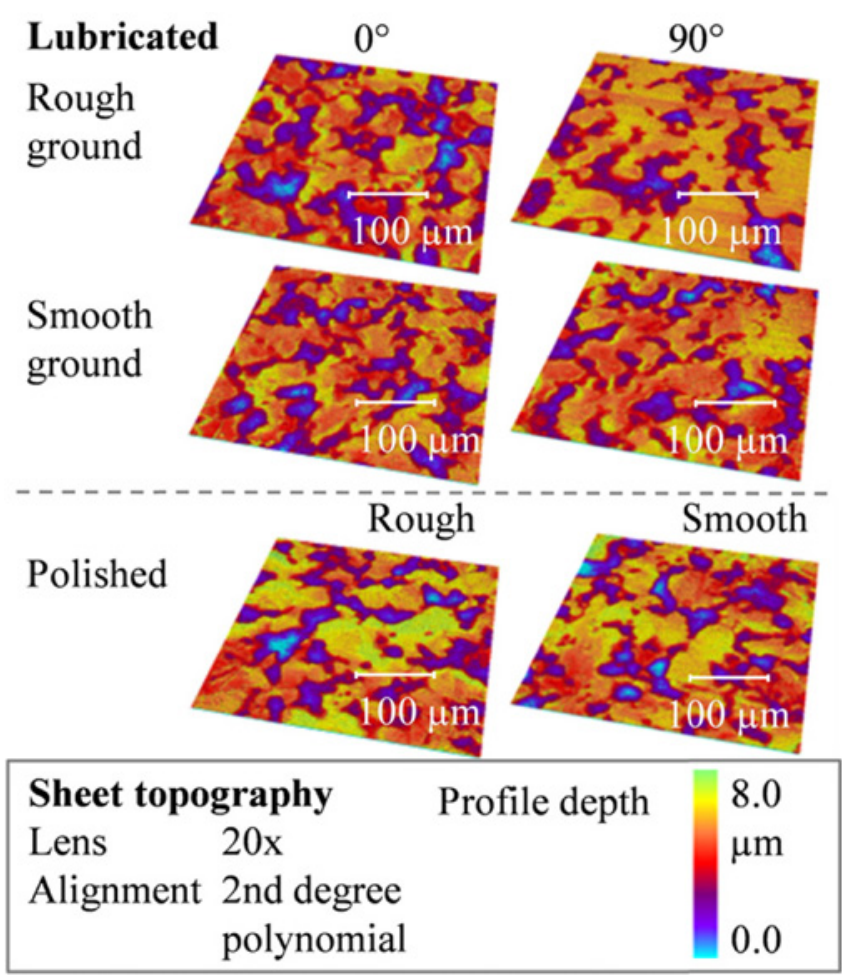

Fig. 11 Sheet topography for strip 5 after dry strip drawing test 
in order to form lubrication pockets. ${ }^{9}$ As shown in Fig. 7 Friction coefficients under dry conditions the highest friction coefficient occurs under dry conditions with in drawing direction and smooth ground tools. Thus, the expectation that under dry conditions smoother surfaces lead to a lower friction could not be approved for ground topographies. An explanation might be the smaller real contact area between the strip and the friction jaw when the topography is structured transverse. Fig. 12 schematically depicts the grinding marks which influence the area of real contact between tool and strip. For rough and transversal ground friction jaws the real contact area is smaller compared to the smooth and in drawing direction ground tools. Hence, the size of the target area for adhesion occurrence is reduced. According to the adhesion theory the friction stress is proportional to the real contact area. ${ }^{10}$ Investigations for dry friction reveal an increasing friction when the real contact area rises. ${ }^{11}$ Furthermore, the interruption of the direct contact (Fig. 12) resulting from the grinding grooves might contribute to an adhesion reduction. An increasing size of the real contact area might be the reason why the smooth ground frictions jaws lead to slightly higher friction coefficients than the rough ground tools. Under dry conditions, the lowest friction is achieved by the polished tool surfaces. Thus, an undirected topography has a positive influence on the tribological conditions in lubricant free processes. The polished tool surface has less roughness peaks at which an interlocking with the peaks of the sheet metal topography is possible. There is less ploughing of contacting asperities ${ }^{12}$ when applying a polished surface. Less adhesion (Fig. 9) and low friction are the consequences. The transversal ground tools reveal less adhesion and reduced friction compared to the other ground tests. With specific adaptations of the grinding marks height and distance between the marks, it might be possible to achieve a further friction decrease.

\section{Summary and Outlook}

Under dry conditions the direct contact between the tool and the workpiece leads to increasing friction and wear. To accomplish dry forming processes, there is a need of basic investigations of the interactions in lubricant free forming operations. Within this study the influence of varying tool surface properties was investigated. In flat strip drawing tests the tribological behavior of ground and polished friction jaws was evaluated under dry and lubricated conditions. Analyzing the lubricated test series a higher friction reveals for the (a) Rough ground, $90^{\circ}$

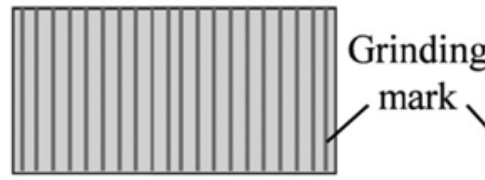

\section{Contact area}

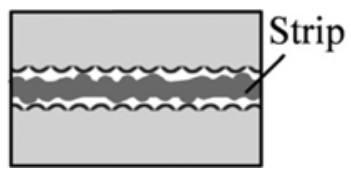

(b) Smooth ground, $0^{\circ}$
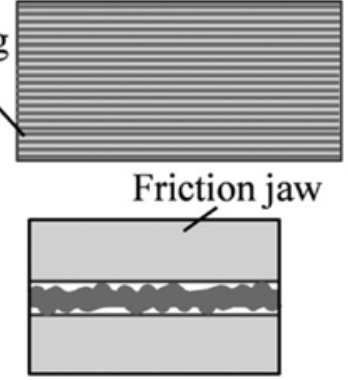

Fig. 12 Schematic contact areas for ground friction jaws rough ground surfaces. Comparing the smooth ground and polished tool surfaces minor changes can be detected. In general, with lubricated strips the orientation of the preferential direction has slight influence on the friction compared to the roughness. There are indications that a too smooth surfaces leads to a rising friction. The results of the strip drawing tests reveal a more than doubled friction coefficient under dry conditions. Comparisons of the experimental results show clear differences between the investigated tool surface properties. First, the orientation of the grinding marks and the surface structure has remarkable influence on the friction under dry conditions. Grinding marks transverse to the drawing direction lead to decreasing friction. The roughness of the friction jaws has minor influence compared to the preferential direction. Applying an undirected surface structure leads to lower friction, even if the roughness is approximately at the same level. This study has shown that a favorable orientation of the surface structure lead to a reduced friction under dry conditions. Future investigations with structured tools will be performed to define the range in which the size and orientation of structural elements are able to determine the friction.

\section{ACKNOWLEDGEMENT}

The authors thank the German Research Foundation (DFG) for supporting this study by funding the SPP 1676 project ME 2043/43-1.

\section{REFERENCES}

1. Makinouchi, A. and Kawka, M., "Prediction of Geometrical Defects in Sheet Metal Forming Processes by Semi-Implicit FEM," Studies in Applied Mechanics, Vol. 43, pp. 265-281, 1995.

2. Kirkhorn, L., Frogner, K., Andersson, M., and Ståhl, J.-E., "Improved Tribotesting for Sheet Metal Forming," Procedia CIRP, Vol. 3, pp. 507-512, 2012.

3. Bay, N., Azushima, A., Groche, P., Ishibashi, I., Merklein, M., et al., "Environmentally Benign Tribo-Systems for Metal Forming," CIRP Annals-Manufacturing Technology, Vol. 59, No. 2, pp. 760-780, 2010.

4. Vollertsen, F. and Schmidt, F., "Dry Metal Forming: Definition, Chances and Challenges," Int. J. Precis. Eng. Manuf.-Green Tech., Vol. 1, No. 1, pp. 59-62, 2014.

5. Kirkhorn, L., Bushlya, V., Andersson, M., and Ståhl, J.-E., "The Influence of Tool Steel Microstructure on Friction in Sheet Metal Forming," Wear, Vol. 302, No. 1-2, pp. 1268-1278, 2013.

6. Meiler, M. and Jaschke, H., "Lubrication of Aluminium Sheet Metal within the Automotive Industry," Advanced Materials Research, Vol. 6-8, pp. 551-558, 2005.

7. Birkert, A., Haage, S., and Straub, M., "Umformtechnische Herstellung Komplexer Karosserieteile: Auslegung von Ziehanlagen,” Springer-Verlag, pp. 179-180 and 207-209, 2013. 
8. Severo, V., Vilhena, L., Silva, P., Dias, J., Becker, D., et al., "Tribological Behaviour of W-Ti-N Coatings in Semi-Industrial Strip-Drawing Tests," Journal of Materials Processing Technology, Vol. 209, No. 10, pp. 4662-4667, 2009.

9. Batalha, G. and Stipkovic, F. M., "Quantitative Characterization of the Surface Topography of Cold Rolled Sheets-New Approaches and Possibilities," Journal of Materials Processing Technology, Vol. 113, No. 1, pp. 732-738, 2001.

10. Bowden, F. P., Tabor, D., and Freitag, E. H., "Reibung und Schmierung Fester Körper,” Springer Berlin Heidelberg, pp. 13-145, 1959.

11. Leu, D.-K., "A Simple Dry Friction Model for Metal Forming Process," Journal of Materials Processing Technology, Vol. 209, No. 5, pp. 2361-2368, 2009.

12. Hol, J., Alfaro, M. C., De Rooij, M., and Meinders, T., "Advanced Friction Modeling for Sheet Metal Forming," Wear, Vol. 286-287, pp. 66-78, 2012. 